\title{
Computer Assisted Personal Interviewing: A Method of Capturing Sensitive Information
}

\begin{abstract}
This paper will discuss how Computer

Assisted Personal Interviewing (CAPI)

coped with collecting sensitive data in a

difficult interview situation. A recent

research project, funded by Scottish

Homes (a UK Government Housing

Agency for Scotland) used the CAPI

technique to collect information on

home ownership at the margins of affordability. The

project used an innovative joint approach between the academic sector and a leading UK survey consultancy.

It could be argued that a more sensitive method of collecting this sort of information would have been indepth interviews, which could then have been analysed using qualitative research methods. The paper will

discuss the outcomes of using CAPI and quantitative

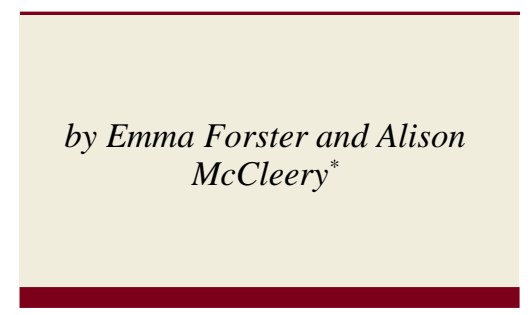

research methods in such a sensitive project.

It is suggested that the use of CAPI has achieved a better response rate on sensitive questions than other techniques would have. The use of CAPI has a number of well-known advantages, such as improvements in data quality and turnaround times. This paper will assess whether CAPI can deliver in a number of interview conditions or if its potential benefits will be realised only under certain conditions. It will critically review how the quantitative method worked in this specific situation before placing the discussion in its wider research methodology and research environment context.
\end{abstract}

\section{Introduction}

This paper firstly will review the literature with a view to describing the current state of the art of CAI, secondly it will describe a Scottish housing project which used CAPI and consider the quality of data output, and thirdly, it will draw conclusions about the use of CA(P)I on the basis of the authors' own findings but also placing the discussion in its wider research methodology and research environment context.

The questions which this paper seeks to explore are broadly:

* Is CAPI suitable only for large projects ?

* Is CAPI good with sensitive data?

* Does use of CAPI improve data quality?

* Can CAPI substitute for qualitative research in a contract research environment?

These types of questions have not been asked before as, arguably, studies on data quality have been too restricted. Furthermore, it is suggested that the potential of computer-assisted data collection methods has not been fully utilised. This paper explores whether quantitative research could be regarded as a universal solution.

\section{Part 1: Literature: Previous users of CAPI}

Compared to even a few years ago, Computer Aided Interviewing (CAI) is now relatively widespread and mature. A move to CAI can, for example, lead to improvements in data quality and turnaround times; it can even make possible surveys that would not otherwise be contemplated. For these and other reasons, many survey organisations and clients have been persuaded that CAI is where the future of survey research lies.

Indeed for almost every traditional approach to survey data collection there is now a computer assisted alternative. The two most widespread are Computer Assisted Telephone Interviewing (CATI) and Computer Assisted Personal Interviewing (CAPI) (Collins \& Sykes, 1998). Just because CAPI/CAI is so widespread these days, there is no longer much research 
which compares them as modes to the more traditional modes. Instead the focus of the literature has shifted to improving CAI, as for instance Bulmer et al. (1998), away from questioning the intrinsic comparative value of the mode itself.

However, due to the shift which has occurred in the way survey data are collected with telephone surveys and, to a lesser degree, mail surveys now being more extensively used, this has stimulated a limited amount of empirical research on the influence of the data collection method on data quality. De Leeuw et al. (1996) compare a mail, a telephone, and a face-toface survey and found that the different data collection methods did have an effect. There is less research however on the question of whether to adopt CAI but more on what effect it has and how this might be mediated.

\section{Disadvantages of CAPI and CAI in general}

There is conflicting evidence on the impact of CAPI on data quality. Collins \& Sykes (1998) find little evidence of clear improvement as yet. Furthermore, despite general acceptance of CAI in the literature, it is recognised that paper and pen interviewing (PAPI) still has its role. The promise of CAI will be realised only under certain conditions and CAPI is not a panacea.

Face to face interviews and CAPI as a method of data collection also have weaknesses associated with their usage. For instance Blyth (1998) lists the hours needed to be worked by the interviewers; falling response rates obtained by this method; and personal safety considerations amongst others, all factors that would militate against the increased use of this method. To this list Blyth (1998) adds equipment cost and software/hardware/data interaction as well as the need for batteries, as major issues to be considered in CAPI.

Although, as will be seen later, there are ways round the capital investment and overheads barriers to the use of CAI, nevertheless these types of hardware and software issues associated with CAPI must be fully taken on board before the decision is taken to use CAPI as a data collection method. Finally, the quality and accessibility of the output data from CAI has been questioned. This is because CAI does not eliminate human error, which where CAPI is concerned, simply manifests itself in a different way as compared with PAPI. Routing mistakes may mean that whole questions are missed in every interview, whereas in PAPI the interviewer may inadvertently turn over two pages together and may miss a whole page but not in every case or at least not the same error in every case i.e. PAPI is likely to be associated with a series of random inconsistent errors, while CAPI is likely to be associated with a single consistent serious error affecting every interview schedule. However, it is suggested that the latter is highly responsive to improvement as a result of piloting the questionnaire and training of interviewers.

Currently one of the disadvantages of CAPI is that the non-technical reader finds the content, structure and workings of a CASIC questionnaire much more difficult to understand (Bulmer et al., 1998). The growing possibilities of computer hardware and software associated with technological advance have made it possible to develop very large, and complex electronic questionnaires. As a consequence, it has become more and more difficult for developers, interviewers, supervisors, and managers to keep control of the content and structure of CAI instruments. Various attempts have been made to render these CAI questionnaires intelligible to non-specialists. Recently a more comprehensive attack on the documentation problem was launched. This project has been named TADEQ (A Tool for Analysing and Documenting Electronic Questionnaires), Manners \& Bethlehem, 1999 ${ }^{1}$. The TADEQ project proposes to develop a flexible tool for documenting and analysing electronic questionnaires. This tool aims to be neutral so it will be possible to use it in combination with existing computer assisted interviewing (CAI) systems. As a documentation tool, it must be able to produce a human-readable presentation of the electronic questionnaire. TADEQ will produce two types of output: a paper version of the documentation, which can be used e.g. by either interviewers or managers; and an electronic version of the documentation, in some kind of hypertext format, allowing developers or researchers to scrutinise the contents and structure of the questionnaire.

This development poses a conundrum for data archivists: should they adjust their systems to include the tool to convert CAI questionnaires into this standard format once they have received them, or should they get data depositors to do this before they submit their questionnaire? The result of such a tool is that it produces standardisation of survey documentation and so is advantageous for data archivists in the long run.

\section{Advantages of CAPI}

Dent (1999) does recognise that the well-known advantages of technology are that they provide an improved research quality, a quicker turnaround and easier integration with other activities, for instance management reporting and marketing approaches. He further states that the main reasons for the use of CAI include managing complexity of data, of samples and of reporting and maintaining records and files. These have been comprehensively illustrated elsewhere. Bulmer et al. (1998) in their finding that the introduction of computer assisted survey information collection (CASIC) has made technically 
feasible a much higher level of questionnaire complexity than was possible in paper and pencil days. This confirms it is literally the case that much of today's more 'serious' work could not be otherwise achieved without CAI.

De Leeuw et al. (1995) reviews the evidence of the effect of computer assisted interviewing on data quality and find that there are clear advantages of CAI in two main areas: survey data quality; and acceptance of the computer by respondents and interviewers. Their main conclusions are that computer-assisted data collection methods are accepted by both respondents and interviewers, and that survey data quality improves, especially when complex questionnaires are used. By 1999, in a discussion of the widespread market penetration of CATI and to a lesser extent CAPI, De Leeuw has added lower costs to the previously identified advantage of improved data quality.

Although a study by Hox \& De Leeuw (1994) shows that response to mail surveys has been improving recently, nevertheless face-to-face surveys continue to achieve the highest response rates. Given Dillman et al.'s (1993) finding that asking potentially difficult and/or objectionable questions lowers the response rate, a CAPI approach which combines good results on sensitive questions with the traditional high response rate of face-to-face interviews should now be the method of choice. Furthermore, the use of technology gives a professional image, and CAPI is generally liked by respondents, while it intrigues many elderly respondents. Research should therefore concentrate on further reducing human error associated with CAPI. This present paper offers a step along the way to producing more research on face-to-face methods, producing additional research into non-response in face-to-face surveys.

Already a major advantage of CAPI is the way in which it is able to reduce potential interviewer and respondent error. Routing errors are eliminated because the script automatically routes to the correct questions. This ensures that data are generally more complete, can considerably reduce the number of 'non-responses' and, correspondingly, the need for corrective editing (or even re-contacting respondents) later on. CAPI also has the ability to 'range-check' data and carry out logic and consistency checks during the interview. Either 'hard' or 'soft' checks are set, to query or confirm key pieces of data with the respondent. In this project for Scottish Homes CAPI was used to check financial data during the interview and clarify whether figures relate to pounds or pence. Ranges were set for key pieces of financial data and discrepancies queried with the respondent if they fell outside certain ranges. Although we did not use this facility in this study, CAPI can also be used to calculate and provide derived variables during the course of the interview (which can then be fed back to the respondent or queried with them, as appropriate).

Returning to the matter of sensitive questions, there is limited evidence that CAPI is better than PAPI for sensitive questions. Few studies have looked at this. Those that have compared the same questions and different collection modes have tended to compare between CAI methods and rather than between PAPI and CAPI.

When looking at various modes of survey data collection which had to ask difficult or sensitive questions, it was found by Tourangeau \& Smith (1996) that the mode of data collection did indeed affect the level of reporting of sensitive behaviours. This study compared three methods of collecting survey data about sexual behaviours and other sensitive topics: computerassisted personal interviewing (CAPI), computer-assisted self-administered interviewing (CASI), and audio computerassisted self-administered interviewing (ACASI). It was found that the three mode groups did not differ in response rates, but both forms of self-administration tended to reduce the disparity between men and women in the number of sex partners reported. Self-administration, especially via ACASI, also increased the proportion of respondents admitting to the use of illicit drugs. This study also highlighted the importance of the closed answer options in determining the response. Thus it is suggested that open answers, although time-consuming to code, may produce more unbiased answers in answering difficult or sensitive questions.

Other evidence (De Leeuw, 1999) points to that perceived confidentially playing a role in obtaining higher response rates. Earlier research by De Leeuw et al. (1995) concluded that this is an under-researched area. The authors' own survey, while it does not give definitive evidence as it does not use a comparison of methods, nevertheless does lend weight to the argument that use of CAPI gets a good response rate on sensitive questions. De Leeuw (1999) established from her review that there is a greater willingness to report extreme views using CAPI.

MORI Scotland have found, when comparing data from paper based and CAPI surveys, that the problem of non-response to specific questions is significantly reduced, and that some sensitive information is collected more fully (such as household income) with CAPI. For example, in transferring the national MORI Omnibus survey from paper to CAPI, it was found that the proportion agreeing in principle to being re-contacted rose from $77.4 \%$ to $80.8 \%$, and the proportion refusing to declare a household income declined from $16.8 \%$ to $14.1 \%$. However, there is no evidence that, overall, using CAPI has a significant 
effect one way or another on respondent willingness to participate in surveys.

What is, however, certain is that keying errors associated with data entry are very much reduced since data entry is done once, during the interview, rather than by coding onto paper and subsequently transferring responses to computer. Even with $100 \%$ verification, errors of $0.05 \%$ on some variables may be expected where one is interpreting hand-written numbers; experience to date suggests that fewer errors are associated with CAPI.

\section{Summary of advantages and disadvantages of CAPI}

Thus it appears from the literature that CAPI is good for capturing sensitive data, has a fast turnaround time (good for the short deadlines that are associated with contract research) and generally improves data quality (although there is conflicting evidence on this). One of the main disadvantages is cost: the hardware and software is expensive and then there is the interviewer training over and above. This is likely to limit the use of CAPI to commercial survey companies with a large throughput which can afford overheads by spreading the capital investment.

Furthermore, it is worth stressing at this point that CAPI and more generally CAI do not in themselves address many of the common problems of collecting survey data for the quantitative studies and furthermore cannot pretend to emulate the painstaking detail of qualitative interviewing. Nevertheless, it is also, paradoxically, time to say that the conclusion reached from the available literature is that many projects/surveys could not be done with such accuracy, and some not done at all, without CAI. In particular those surveys which require complex routing but need to be carried out in a fairly short interview time.

\section{Part 2: Project description and results}

Brief description of project

The purpose of this research was to:

1. develop an understanding of the issues concerning poorer owner occupiers, and identify what greater role information could play in attaining more successful housing outcomes;

2. undertake a detailed case study of owners in South Rogerfield on Glasgow's eastern periphery. Specifically the aims of the case study were to:

* analyse the factors, both immediate and contextual, which influence the decision to buy;

* produce an evaluation of the retrospective understanding of the owner's responsibility in respect of common repairs;

* determine what information had been used in the process of buying, and of that identify information deemed to have been useful and information considered misleading or unhelpful at each stage in the decision;

* assess the role that information or the lack of it played during any difficulties regarding repair bills, financial

difficulties, redundancy; and

* identify examples of best practice where provision of information helped avoid common pitfalls and where lack of information obscured common pitfalls which happen to those buying on limited budgets.

3. Catalogue the available information for homebuyers before and after they buy their home.

The actual results of the project are reported elsewhere in Forster and McCleery (1999a, 1999b).

South Rogerfield was identified as the survey area by Scottish Homes on account of the high number of repossessions: between 1987 and 199349 houses in the estate were repossessed by lenders: this is equivalent to $20 \%$ of the total number of properties. Together South and North Rogerfield form one of the fourteen neighbourhoods which make up the sprawling peripheral housing estate of Easterhouse on Glasgow's north-eastern perimeter, as shown on location maps 1 and 2. Comprising circa 300 housing units, South Rogerfield consists of 3-storey tenement blocks built in the late 1950s and arranged in either rows or quadrants, predominantly with continuous frontages. On the instructions of Glasgow District Council, the properties were sold off and improved in about 1985 by two firms of property developers, Crudens and Barratt, although twenty or so properties pepper-potted throughout are still council-owned, while six are in housing association shared ownership. The modernisation carried out by the developers included storey height reduction, new roofs, double glazing, new bathrooms and central heating. 
Map 1: Location of survey area within Scotland

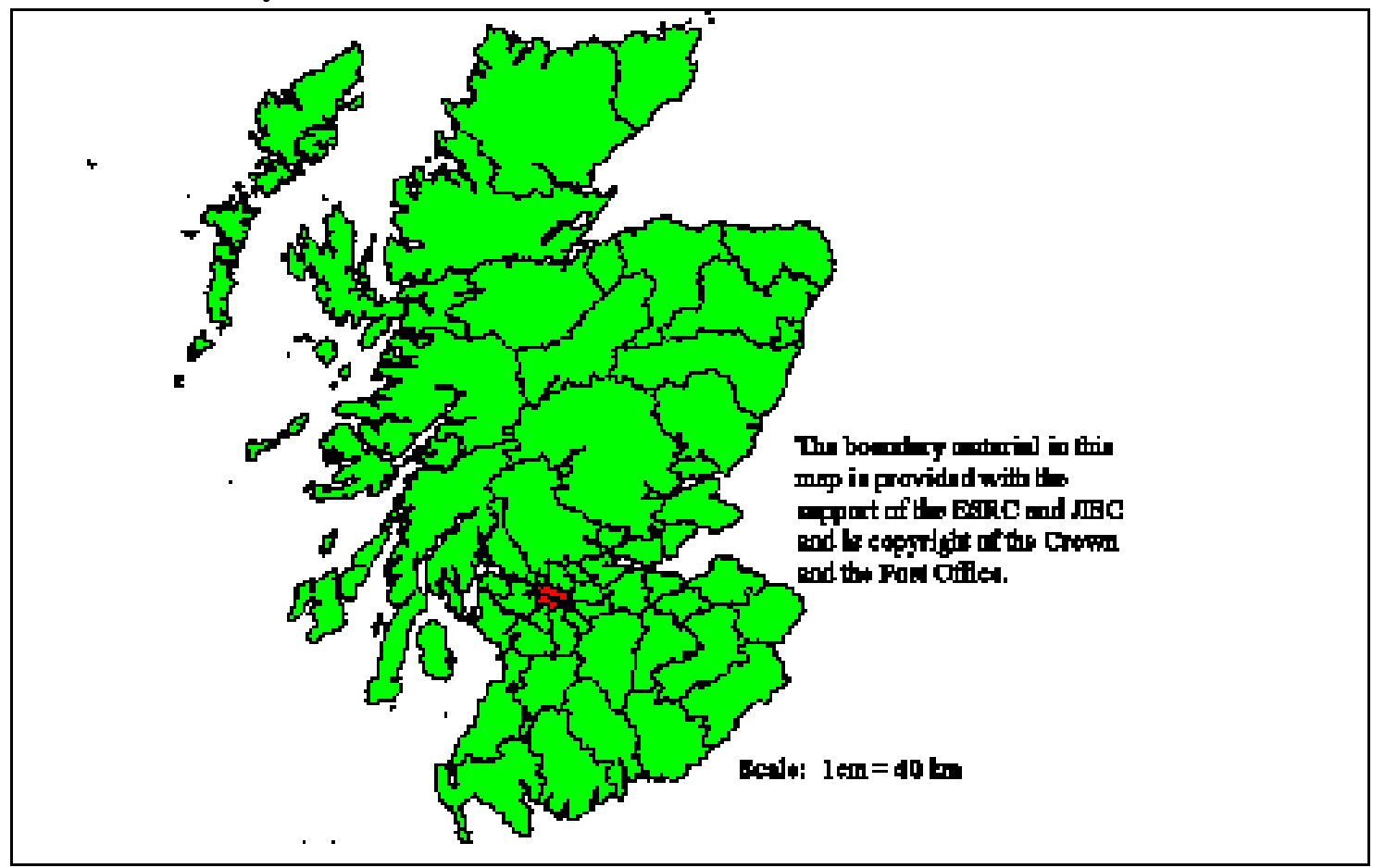

Map 2: Location of Easterhouse estate, Glasgow, Scotland

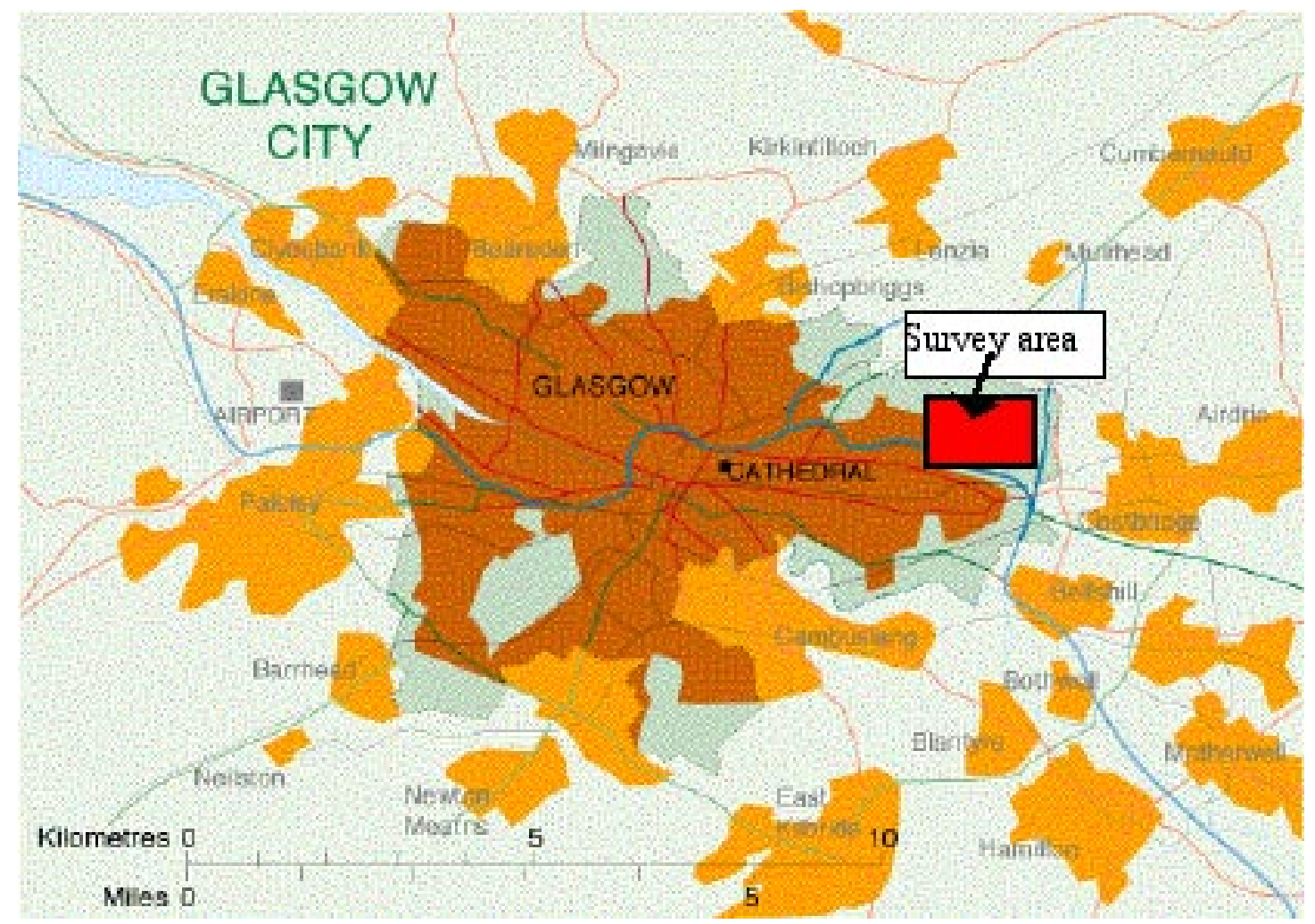

Source: After http://www.scotland.gov.uk/library/documents3/fs12-34.htm Local Government in Scotland, Fact Sheet 12, Scottish office 
Establishment of the sample was not straightforward, but the eventual response rate was very satisfactory for an area of this type. After initial confusion as to how many flats there were in South Rogerfield, 138 full interviews with owner-occupiers were obtained. However, 48 more households, all occupying rented housing, were asked a much more limited list of questions.

If the 41 sheltered and vacant properties are subtracted from the total count, the number of 'valid and occupied' flats comes to 308. From these 186 interviews were obtained, 138 with owners and 48 with renters, giving a total response rate of $60 \%$. A fuller breakdown of response types is provided in Table 1.

Table 1: Response rate
\begin{tabular}{|l|l|l|}
\hline Total addresses identified & 349 & \\
\hline Sheltered or vacant & 41 & \\
\hline 'Valid and occupied' (Used as base) & $\mathbf{3 0 8}$ & \\
\hline Interview with owner & 138 & $45 \%$ \\
\hline Interview with tenant & 48 & $16 \%$ \\
\hline Overall response rate & $\mathbf{1 8 6}$ & $60 \%$ \\
\hline $\begin{array}{l}\text { Refusal (including not interested } \\
\text { and too busy) }\end{array}$ & 45 & $15 \%$ \\
\hline Too ill to take part & & \\
\hline Insufficient English & 2 & $1 \%$ \\
\hline No contact after 4 calls & 1 & $1 \%$ \\
\hline
\end{tabular}

The data from the owner-occupiers was collected by MORI Scotland using Computer Aided Personal Interviewing (CAPI).

\section{Choice of method}

This section begins by defending the choice of CAPI as the survey method. Thereafter the experience of using CAPI is described, prior to a discussion of the extent to which the reality of using the method matched expectations.

First the choice was made between qualitative and quantitative. Sensitive questions are often dealt with in in-depth interviews - qualitative methodologies. The following section explains why qualitative was considered unsuitable for us in this project. A method was needed that produced a quick turnaround. The whole project ran only for 3 months and the data collection phase was allocated only 3.5 weeks, with a draft of the survey results needed shortly after the data collection was finished. Qualitative interviews would have surely discovered more in-depth information on the topic in question but could not have been collected nor analysed in the time allowed. Quantitative method was chosen primarily because of the time-scale. Due to the constraints of research work in a research contract environment, the future of qualitative research in that setting is questionable. Increasingly today, the nature of contract research demands quantitative data which can be analysed statistically and held in data archives for future comparability.

Moving on to discuss the specific choice of CAPI. CAPI has a good response rate on sensitive questions (Tourangeau \& Smith, 1996; De Leeuw, 1999). Yet sensitive data is in the past thought to be better collected in a self-completion method. Yet, CASI has a lower response rate than face-to-face, and has a slower turnaround time. As is seen above in the literature review, the fast turnaround time is one of CAPI's main advantages.

Our expectations in choosing CAPI for this survey were that:

* It would catch the client's imagination to win the contract in the first place

* CAPI would help achieve first time round a 60-70\% response rate needed in connection with the blanket coverage in a small area, (it would not be possible to re-sample to improve the response rate - therefore it needed to be possible to get a fairly high response rate straight off.) 
* Fast turnaround time, in particular it would help speed up the stage between the end of the survey and obtaining the data

* would cut down on data input errors

* Allow complex routing through debt, income, mortgage/endowment payments and repair sections yet it was envisaged that each interview should not last more than 30 minutes.

In summarising the aims of chosen survey method, the nature of the survey demanded a high response rate. The area under study and therefore size were very small and $100 \%$ blanket coverage sought. Furthermore, an important objective of the study was to collect as much data as possible on sensitive questions relating to income, mortgage and other house-related payments, debt etc.

\section{Choice of joint approach}

A collaboration was chosen between a survey company and academic institution, primarily because it was felt that this difficult interview situation asking sensitive questions would need very highly trained and very experienced interviewers. The tight deadlines necessitated this approach, as there was no time for training of interviewers. Not only professionalism and timesaving but cost was an important factor too. This strategic approach avoided the initial expensive investment required in hardware and software i.e. the up-front costs mentioned earlier which are problematical for resource-lean UK academic institutions.

\section{Outcomes of choice of CAPI}

In fact, our expectations of use of CAPI as a data collection method were exceeded as we got better response rates, and lower refusals rates than we expected2. CAPI proved successful in terms of data quality and a high response rate on sensitive question. Our survey differs from the common experience that asking potentially difficult and/or objectionable questions lowers the response rate as found by Dillman et al. (1993).

The refusals to answer sensitive questions did not rise above 6.5\%. The question that had the biggest refusal rate was the income question with 9 households refusing to give this information. Income was asked only in bands so as to improve the response rate and this seems to have worked as there was a high level of response to this question.

An examination of the pattern and number of refusals reveals that it was the same few households that account for most of the refusals. A full list of the questions where refusals occurred is in appendix 1 and the breakdown of the number of refusals is found in appendix 3. A further examination was made of the characteristics of these people and it was found that they did not fall into one demographic or economic group but were scattered between these. Full results of the testing of characteristics of the people who refused to answer some of the questions are to be found in appendix 2. Overall, it was shown that there were very limited refusals in the income and debt questions.

So, in summary, the total refusal rate remained low throughout the survey. Possible reasons for this include professionalism of the highly trained interviewers, the perceived higher confidentiality that CAPI gives the respondents. However, there was not a question on the interviewees attitude to CAPI in the questionnaire and so it is only possible to speculate on this.

While the fairly high response rate overall (Table 1) was pleasing for the researchers, it was not on the whole unexpected and was in conjunction with the fast turnaround time the reason that this method was chosen. However, what was thought to be unusual and not mentioned elsewhere in the literature was that the survey was a fairly small-scale one. Normally CAPI is presented only as cost-effective in large-scale data surveys. Also unexpected was the high response rate to the sensitive questions.

Lessons to learn/Unavoidable problems

As the literature made clear, CAPI is not foolproof and is only as good as the interviewers who administer it and the programmers who set up the routing. In this particular survey two questions were completely missed from every interview due to a fault in the routing. Because of the nature of contract research, with limited budgets and tight time-scales there was no pilot of this survey and only limited testing of the routing before the interview schedule went into the field.

CAPI can arguably improve on PAPI by improving turnaround without any loss of data quality or even an improvement in data quality, in particular with sensitive questions. But for reasons stated earlier use of CAPI has to date been favoured for large studies only. Blyth predicted in 1998 that in the future CAPI would be most relevant for big international players and for very large surveys. He felt that non-CAPI will gravitate more quickly to telephone and that this will result in only a small number of field-only CAPI companies. However, our survey offers a less limited future for CAPI in that it proved successful for a smallish study in which an academic institution sub-contracted the data collection to a commercial concern. 


\section{Conclusions}

In summary:

* CAPI not panacea (although better than PAPI)

* Not a replacement for qualitative methods

* Appropriate for certain data in certain contexts e.g. can achieve good results with sensitive data

* Further research into how even better advancements in CAPI is now appropriate

* Involves high-level of investment - up-front costs- and so is not for everyone - although strategic studies to this problem are possible (as we have shown).

* Previously better for large-scale studies, but especially when handling sensitive data, possible for small-scale studies too (as we have shown).

CAPI was the most suitable method for use in this contract research project primarily because it gets data quickly. However, additional advantages also emerged. The surprising finding was CAPI was useful and cost-effective in small-scale data collection situations too. The combination between academics and market research survey company worked well. The resultant high response rate and low refusal rates commends this method for use in other similar interview situations. But of course, without conducting the same study again using PAPI, it is impossible to conclusively say whether it was CAPI alone that led to high response rate and low refusal rate. Blyth (1998) points out that with increasingly fragmented populations and busier lifestyles we need to use a mix of technologies to obtain maximum response from our survey population. As Blyth (1998) rightly points out the focus should be on the answers and not the media, however, it is important to consider media in the context of which media gives the most (highest quality) answers. It is also necessary to adjust the media according to the research environment context, although in doing so we must not lose sight of issues of research philosophy and quality.

\section{Acknowledgements}

The authors would like to thank Scottish Homes, the funders of this research work 'Housing Information and Advice and Home Ownership at the Margins', and also MORI, Scotland who carried out the survey work and to Simon Braunholtz in particular.

Glossary

$\begin{array}{ll}\text { Computer Assisted Personal Interviewing } & \text { CAPI } \\ \text { Hand-Held Assisted Personal Interviewing } & \text { HAPI } \\ \text { Computer Assisted Telephone Interviewing } & \text { CATI } \\ \text { Computer Assisted Self Interviewing } & \text { CASI } \\ \text { Computer Assisted Interviewing } & \text { CAI } \\ \text { Computer Assisted Data Input } & \text { CADI } \\ \text { Paper And Pen Interviewing } & \text { PAPI } \\ \text { Computer-Assisted Data Collection Methods } & \text { CADAC } \\ \text { Audio Computer-Assisted Self-Administered Interviewing } & \text { ACASI } \\ \text { Computer Assisted Survey Information Collection } & \text { CASIC }\end{array}$

\section{Appendix 1: The questions where refusals occurred:}

QE1. What was the purchase price of this property?

QE3. And roughly how much do you think you could sell this property for now, if you put it on the market?

QE4. From which of the sources on this card did your household get the money to buy this property?

QE8. Apart from money to move in, how much have you borrowed since you moved into the flat for costs to do with the house - for instance repairs, improvements, cookers/fridges etc.?

QE13. At the moment, how much does your household pay each month in mortgage or loan payments?

QE14. How much, if anything, does your household pay in the additional separate endowment part of the mortgage each month?

QF3. How easy or difficult is it for your household to pay the mortgage payments?

QF4. Have you been more than two months behind with your mortgage payments at any time in the past two years ? Please look at this card and tell me the letter next to the band in which you would place your total household income for the year from employment or benefits.

QSV. At the moment do you (or your partner) have any money saved or invested?

QSV2. SHOWCARDS: How much do you (and your partner) have saved together?

Please tell me the letter on this card for the group in which you would place your total savings? 


\section{Appendix 2: Who refused to answer ?}

In total 33 refusals to 11 questions by 14 households.

Case number 113 refused 7 questions

Case number 41 refused 5 questions

Case number 72 refused 4 questions

Case number 94 refused 3 questions

Case number 26 refused 2 questions

Case number 55 refused 2 questions

Case number 99 refused 2 questions

Case number 130 refused 2 questions

Case number 68 refused 1 question

Case number 69 refused 1 question

Case number 70 refused 1 question

Case number 100 refused 1 question

Case number 109 refused 1 question

Case number 123 refused 1 question

\begin{tabular}{|c|c|c|c|c|c|c|c|c|c|c|}
\hline & $\begin{array}{l}\text { Part } \\
\text { time } \\
\text { and } \\
\text { full- } \\
\text { time } \\
\text { worker }\end{array}$ & $\begin{array}{l}\text { House- } \\
\text { wife } \\
\text { and } \\
\text { full- } \\
\text { time } \\
\text { worker }\end{array}$ & $\begin{array}{l}\text { Two } \\
\text { retired } \\
\text { people }\end{array}$ & $\begin{array}{l}\text { Four } \\
\text { full } \\
\text { time } \\
\text { workers }\end{array}$ & $\begin{array}{l}\text { Three } \\
\text { full } \\
\text { time } \\
\text { workers }\end{array}$ & $\begin{array}{l}\text { One } \\
\text { full } \\
\text { time } \\
\text { worker }\end{array}$ & $\begin{array}{l}\text { One } \\
\text { full- } \\
\text { time } \\
\text { worker } \\
\text { and one } \\
\text { LT sick }\end{array}$ & $\begin{array}{l}\text { One } \\
\text { part- } \\
\text { time } \\
\text { worker } \\
\text { only }\end{array}$ & $\begin{array}{l}2 \text { full- } \\
\text { time, } 1 \\
\text { part- } \\
\text { time } \\
\text { and 1 } \\
\text { student }\end{array}$ & Total \\
\hline Total & 3 & 3 & 1 & 1 & 1 & 2 & 1 & 1 & 1 & 14 \\
\hline
\end{tabular}

\begin{tabular}{|c|c|c|c|c|c|c|}
\hline \multicolumn{7}{|c|}{$\begin{array}{l}\text { Household sizes of respondent households who } \\
\text { refused to answer any question }\end{array}$} \\
\hline HH Size & 1 & 2 & 3 & 4 & 5 & Total \\
\hline Total & 2 & 3 & 4 & 3 & 2 & 14 \\
\hline
\end{tabular}

\begin{tabular}{|c|c|c|c|c|c|}
\hline \multicolumn{6}{|c|}{$\begin{array}{l}\text { Number of children in respondent households } \\
\text { who refused to answer any question }\end{array}$} \\
\hline $\begin{array}{l}\text { Number of } \\
\text { children }\end{array}$ & 0 & 1 & 2 & 3 & Total \\
\hline Total & 8 & 3 & 2 & 1 & 14 \\
\hline
\end{tabular}

\begin{tabular}{|l|c|c|c|c|c|}
\hline \multicolumn{6}{|c|}{ Household types of respondent households who refused to answer any question } \\
\hline $\begin{array}{c}\text { Household } \\
\text { type }\end{array}$ & $\begin{array}{c}\text { Single person } \\
\text { household }\end{array}$ & $\begin{array}{c}\text { Family - two } \\
\text { adults and child }\end{array}$ & $\begin{array}{c}\text { Family - two } \\
\text { adults and more } \\
\text { than one child }\end{array}$ & $\begin{array}{c}\text { Older couple - } \\
\text { non-dependent } \\
\text { or no children }\end{array}$ & Total \\
\hline Total & 2 & 4 & 3 & 5 & 14 \\
\hline
\end{tabular}




\section{Appendix 3: The number of refusals}

\begin{tabular}{|l|c|c|c|c|}
\hline QE1 What was the purchase price of this property? \\
\hline & Frequency & Percent & $\begin{array}{c}\text { Valid } \\
\text { Percent }\end{array}$ & $\begin{array}{c}\text { Cumulative } \\
\text { Percent }\end{array}$ \\
\hline Refused & 2 & 1.4 & 66.7 & 66.7 \\
\hline Don' t know & 1 & .7 & 33.3 & 100.0 \\
\hline Total & 3 & 2.2 & 100.0 & \\
\hline Missing & 135 & 97.8 & & \\
\hline Total & 138 & 100.0 & & \\
\hline
\end{tabular}

QE3 how much do you think you could sell this property for now?

\begin{tabular}{|l|c|c|c|c|}
\hline & Frequency & Percent & $\begin{array}{c}\text { Valid } \\
\text { Percent }\end{array}$ & $\begin{array}{c}\text { Cumulative } \\
\text { Percent }\end{array}$ \\
\hline Refused & 1 & .7 & 9.1 & 9.1 \\
\hline Don' t know & 10 & 7.2 & 90.9 & 100.0 \\
\hline Total & 11 & 8.0 & 100.0 & \\
\hline Missing & 127 & 92.0 & & \\
\hline Total & 138 & 100.0 & & \\
\hline
\end{tabular}

QE4 From which of the sources on this card did your household get the money to buy this property?

\begin{tabular}{|l|c|c|c|c|}
\hline & Frequency & Percent & $\begin{array}{c}\text { Valid } \\
\text { Percent }\end{array}$ & Cumulative Percent \\
\hline Not & 137 & 99.3 & 99.3 & 99.3 \\
\hline Refused & 1 & .7 & .7 & 100.0 \\
\hline Total & 138 & 100.0 & 100.0 & \\
\hline
\end{tabular}

QE8 Apart from money to move in, how much have you borrowed since you moved into the flat for costs to do with the house

\begin{tabular}{|l|c|c|c|c|}
\hline & Frequency & Percent & Valid Percent & Cumulative Percent \\
\hline Refused & 2 & 1.4 & 1.7 & 1.7 \\
\hline Don' t know & 4 & 2.9 & 3.4 & 5.0 \\
\hline None & 113 & 81.9 & 95.0 & 100.0 \\
\hline Total & 119 & 86.2 & 100.0 & \\
\hline Missing & 19 & 13.8 & & \\
\hline Total & 138 & 100.0 & & \\
\hline
\end{tabular}

QE13 how much does your household pay each month in mortgage or loan payments

\begin{tabular}{|l|c|c|c|c|}
\hline & Frequency & Percent & Valid Percent & Cumulative Percent \\
\hline Refused & 2 & 1.4 & 33.3 & 33.3 \\
\hline Don' t know & 4 & 2.9 & 66.7 & 100.0 \\
\hline Total & 6 & 4.3 & 100.0 & \\
\hline Missing & 132 & 95.7 & & \\
\hline Total & 138 & 100.0 & & \\
\hline
\end{tabular}


QE14 How much, if anything, does your household pay in additional endowment

\begin{tabular}{|l|c|c|c|c|}
\hline & Frequency & Percent & Valid Percent & Cumulative Percent \\
\hline Refused & 2 & 1.4 & 5.4 & 5.4 \\
\hline Don' t know & 4 & 2.9 & 10.8 & 16.2 \\
\hline $\begin{array}{l}\text { Nothing, it is included in } \\
\text { figure quoted }\end{array}$ & 31 & 22.5 & 83.8 & 100.0 \\
\hline Total & 37 & 26.8 & 100.0 & \\
\hline Missing & 101 & 73.2 & & \\
\hline Total & 138 & 100.0 & & \\
\hline
\end{tabular}

\begin{tabular}{|l|c|c|c|c|}
\hline QF3 How easy or difficult is it for your household to pay mortgage payments \\
\hline & Frequency & Percent & Valid Percent & Cumulative Percent \\
\hline Easy & 109 & 79.0 & 79.0 & 79.0 \\
\hline Sometimes have difficulties & 23 & 16.7 & 16.7 & 95.7 \\
\hline Often have difficulties & 3 & 2.2 & 2.2 & 97.8 \\
\hline Always have difficulties & 1 & .7 & .7 & 98.6 \\
\hline Don' t know & 1 & .7 & .7 & 99.3 \\
\hline Refused & 1 & .7 & .7 & 100.0 \\
\hline Total & 138 & 100.0 & 100.0 & \\
\hline
\end{tabular}

\begin{tabular}{|l|c|c|c|c|}
\hline QF4 Have you been more than two months behind with your mortgage payments at any time in the past 2 years \\
\hline & Frequency & Percent & Valid Percent & Cumulative Percent \\
\hline Yes & 10 & 7.2 & 7.2 & 7.2 \\
\hline No & 126 & 91.3 & 91.3 & 98.6 \\
\hline Refused & 1 & .7 & .7 & 99.3 \\
\hline Don't know & 1 & .7 & .7 & 100.0 \\
\hline Total & 138 & 100.0 & 100.0 & \\
\hline
\end{tabular}

\begin{tabular}{|l|c|c|c|c|}
\hline \multicolumn{5}{|l|}{ Income Group } \\
\hline & Frequency & Percent & Valid Percent & Cumulative Percent \\
\hline A Under $£ 5,000$ & 3 & 2.2 & 2.2 & 2.2 \\
\hline B $55,000-£ 10,000$ & 11 & 8.0 & 8.0 & 10.1 \\
\hline C Over $£ 10,000-£ 15,000$ & 36 & 26.1 & 26.1 & 36.2 \\
\hline D Over $£ 15,000-£ 20,000$ & 35 & 25.4 & 25.4 & 61.6 \\
\hline E Over $£ 20,000-£ 25,000$ & 19 & 13.8 & 13.8 & 75.4 \\
\hline F Over $25,000-£ 30,000$ & 9 & 6.5 & 6.5 & 81.9 \\
\hline G Over $£ 30,000$ & 9 & 6.5 & 6.5 & 93.5 \\
\hline Don' t know & 7 & 5.1 & 5.1 & 100.0 \\
\hline Refused & 9 & 6.5 & 6.5 & \\
\hline Total & 138 & 100.0 & 100.0 & \\
\hline
\end{tabular}




\begin{tabular}{|l|c|c|c|c|}
\hline QSV Have you (or your partner) savings? \\
\hline & Frequency & Percent & Valid Percent & Cumulative Percent \\
\hline Yes & 42 & 30.4 & 30.4 & 30.4 \\
\hline No & 88 & 63.8 & 63.8 & 94.2 \\
\hline Refused/unsure & 8 & 5.8 & 5.8 & 100.0 \\
\hline Total & 138 & 100.0 & 100.0 & \\
\hline
\end{tabular}

\begin{tabular}{|l|c|c|c|c|}
\hline QSV2 How much do you (and your partner) have saved? \\
\hline & Frequency & Percent & Valid Percent & Cumulative Percent \\
\hline A Under $£ 1,000$ & 8 & 5.8 & 19.0 & 19.0 \\
\hline B $1,000-£ 2,999$ & 10 & 7.2 & 23.8 & 42.9 \\
\hline C £3,000-£4,999 & 8 & 5.8 & 19.0 & 61.9 \\
\hline D $5,000-£ 9,999$ & 1 & .7 & 2.4 & 64.3 \\
\hline E £10,000-£16,000 & 3 & 2.2 & 7.1 & 71.4 \\
\hline F Over £16,000 & 6 & 4.3 & 14.3 & 85.7 \\
\hline Don’ t know & 2 & 1.4 & 4.8 & 90.5 \\
\hline Refused & 4 & 2.9 & 9.5 & 100.0 \\
\hline Total & 42 & 30.4 & 100.0 & \\
\hline Missing & 96 & 69.6 & & \\
\hline Total & 138 & 100.0 & & \\
\hline
\end{tabular}

\section{References}

Blyth, Bill (1998) The Current and Future Use of Technology in European Survey Research, Presentation at Association for Survey Computing (ASC) Compstat Satellite Meeting, New Methods for Survey Research, 21 - 22 August 1998, Chilworth Manor, Southampton.

Bulmer, M. Thomas, R. \& Donagher, P. (1998) Survey Documentation: Representation of CASIC Questionnaires, in New Methods For Survey Research, Edited by A. Westlake et al., Association for Survey Computing, pp 37-48. (http:// www.assurcom.demon.co.uk/Events/C98/)

Collins, M. \& Sykes, W. (1998) The Impact of Computer Assisted Interviewing on UK Survey Research, in New Methods For Survey Research, Edited by A. Westlake et al., Association for Survey Computing, pp 3-12. (http:// www.assurcom.demon.co.uk/Events/C98/)

De Leeuw, E. (1999) The Effect of Computer Assisted Interviewing on Data Quality: A Review of the Evidence, Social Statistics Meeting, Royal Statistical Society, March 16th, 1999.

De Leeuw, E.D.; Hox, J.J.; Snijkers, G. (1995) The Effect Of Computer-Assisted Interviewing On Data Quality - A Review, Journal Of The Market Research Society, 37(4): 325-344.

DeLeeuw, E.D., Mellenbergh, G.J. \& Hox, J.J. (1996) The influence of data collection method on structural models - A comparison of a mail, a telephone, and a face-to-face survey, Sociological Methods \& Research 24(4): 443-472.

Dent, T. (1999) The Impact of CAI on Large and Complex Surveys: Taking Advantage of the New Technology, Presentation at the Impact of CAI on Large and Complex Surveys, 8 January 1999, at Imperial College, London. http:// www.assurcom.demon.co.uk

Dillman, D.A., Sinclair, M.D., Clark, J.R. (1993) Effects Of Questionnaire Length, Respondent-Friendly Design, And A Difficult Question On Response Rates For Occupant-Addressed Census Mail Surveys, Public Opinion Quarterly, 57 (3): 289 304. 
Forster, E. \& McCleery, A. (1999) Housing Information and Advice and Home Ownership at the Margins, Report to Scottish Homes. http://www.scot-homes.gov.uk/

Hox, J.J.; \& De Leeuw, E.D. (1994) A Comparison Of Nonresponse In Mail, Telephone and Face-To-Face Surveys Applying Multilevel Modeling To Metaanalysis, Quality \& Quantity, 28(4): 329-344.

Manners, T. \& Bethlehem, J. (1999) TADEQ: A Tool for Analysing and Documenting Electronic Questionnaires. Presentation at the Impact of CAI on Large and Complex Surveys, 8 January 1999, at Imperial College, London. http:// www.assurcom.demon.co.uk

Scottish Homes (1999) Housing Information and Advice and Home Ownership at the Margins, Scottish Homes: PRECiS No. 85. http://www.scot-homes.gov.uk/indexnext5.html

Tourangeau, R. \& Smith, T.W. (1996) Asking sensitive questions - The impact of data collection mode, question format, and question context, Public Opinion Quarterly, 60(2): 275-304.

1 The TADEQ project is funded under the European Commission's Esprit programme. It is led by Statistics Netherlands and the other partners are the Office for National Statistics, UK; Statistics Finland; Instituto Nacional de Estatística, Portugal; Max Planck Institute, Saarbrucken, Germany. More information on the TADEQ project can be found at:http:// www.blaiseusers.org/tadeq/abouttdq.htm

2 The survey was both of renters and owner-occupiers but only the owner-occupiers were asked a full interview using CAPI. The responses of the owner-occupiers only will be dealt with in this paper.

Emma Forster and Alison McCleery, Dept of Psychology and Sociology, Napier University, Redwood House, 66 Spylaw Road, Edinburgh, EH10 5BR,Scotland, U.K. Telephone: +44 1314555139 Fax: +44 1314555141 e-mail:

e.forster@napier.ac.uk

* Paper presented at:International Association for Social Science Information Service \& Technology, Building Bridges, Breaking Barriers: the future of data in the global network, Toronto, May, 1999. 